\section{Effect of reward on speed of coding for normal and hearing-impaired children'}

LOIS L. ELLIOTT and ANN B. VEGELY, Central Institute for the Deaf, St. Louis, Mo. 63110

Three groups of children who received rewarded practice on a sequentialprocessing-and-memory task, similar to one subtest of the WISC, improved and retained gains on retest after a retention interval. The lowachieving deaf performed less well than the other two groups throughout. Other investigators have inferred that a "specific factor" measured by the coding test is related to reading and language development in normul children. Compounding a deficiency in this skill with an additional sensory handicap, such as deafness, shows the relation more clearly.

The coding subtest of the WISC requires a form of sequential item-by-item information processing in which speed and accuracy are essential for obtaining a high score. Recently, several investigators have noted that normally hearing children of normal intelligence, who have reading problems, generally score poorly on this subtest (Altus, 1956; Graham, 1952; Robeck, 1960; Doehring, 1968). Glasser \& Zimmerman (1967) suggested that a specific factor is responsible for the reliable variance of the coding subtest but Doehring's results, based on many different test measures, indicate that a more general, perceptual dimension may be involved.

It has been shown that deaf children who maintain expected school progress score about average on the coding subtest while deaf children with language learning difficulties score considerably lower. Other investigations have shown: that deaf children usually perform less well than normally hearing children on tasks which require sequential processing of information (Withrow, 1968; Hartman \& Elliott, 1965); that they do not process information as rapidly as normal children (Hartung, 1968; Elliott, Hirsh, \& Simmons, 1967; Olssen, 1967); that the patterning of their reading skills differs from that of normals (Elliott \& Vegely, 1967, 1968); and that they have uneven patterns of subtest scores on standardized intelligence tests (Elliott, 1967). Since it is not known whether these effects should be attributed to features of the general background of these deaf children, or whether they represent inherent impairments in information processing, an experiment was performed to determine whether motivating conditions and opportunity for practice would improve performance on a task similar to the coding subtask. Of interest, also, was the question of whether motivating conditions would eliminate the apparent differences on this type of task between deaf achievers and nonachievers.

\section{METHOD}

The task incorporated basic principles of the coding subtest. Six different experimental forms were devised, each with eight stimuli and eight geometric symbols in the key. One form employed numbers as stimuli in the key (as does the original subtest), three employed letters of the alphabet (A-H, I.P, S.Z), and two employed colors which were arranged in order of hue. The response was always a geometric symbol which could be drawn by one or by two pencil strokes; six different sets of such geometric symbols were devised. A particular set of geometric symbols was always associated with the same form. However, three versions of each form were constructed so that a given stimulus (number or color or letter) was paired with a different geometric symbol on each. The key appeared at the top of the answer sheet above the 112 response boxes (seven rows of 16 elements) which each contained one stimulus from the key (see Fig. 1). The $S$ was required to draw, in each response box, the geometric symbol which was paired with the stimulus in the key. Two minutes were allowed for each trial and a different form was presented on each trial. During each of two sessions, which were separated by 1 week, a child received seven trials. The first six comprised one version of each of the six forms in an order determined by replicated Latin squares. The last (critical) trial at both sessions was a different version of the form given on the first trial. Thus, Trials $1,7,8,14$ (and, in the retest, 16) repeated the same form with randomly assigned versions (with the restriction that the same version was not presented at first and last trials of a session). Test materials were constructed on white $8 \frac{1 / 2}{12} 11$ in. paper and encased in plastic "sheetprotectors." Geometric symbols and numeric and alphabetic stimuli were drawn in black ink while color stimuli were $3 / 4 \times 1 / 4$ in. rectangles of construction paper glued into position. The child used a crayon to mark his responses.

Instructions were given orally to all groups and used a separate practice sheet which contained eight stimuli in the key and 32 response boxes. When the child appeared to understand the task, he was told: "Work as fast as you can. Fill in as many boxes as you can. Ready. Go." At the end of $2 \mathrm{~min}$ he was stopped, his work was examined for incorrect responses, and the "reward schedule" was first introduced. This was a specially prepared test form which had pennies glued to it in such a way that 4 were positioned on the first row, 8 on the second row, and 16 on each remaining row. E placed pennies over correctly completed boxes of S's answer sheet according to the "reward schedule." The child put the pennies into a coin wrapper and the next trial was presented with the reward schedule re. maining clearly visible on the work table. After each trial, earnings were determined

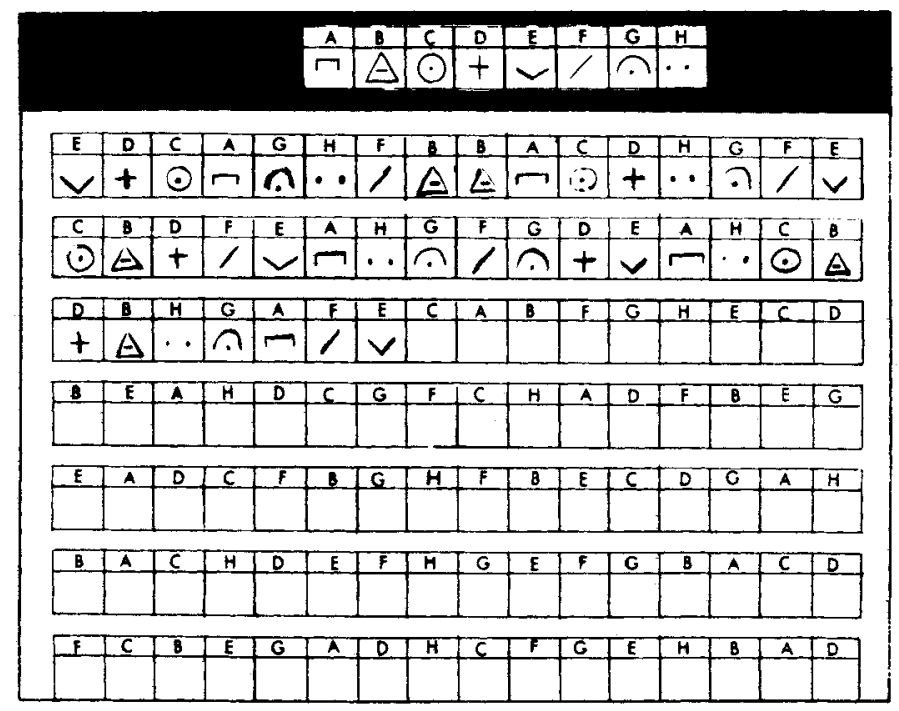

Fig. 1. Sample form partially completed. 
and paid immediately in the same way.

Following the 14th coding trial the child was presented with a form like the others except that it contained only one letter of the alphabet in the key and one geometric symbol. Performance on this trial required speeded motor coordination but not sequential processing of information. All other procedures were the same. Two and one-half months later a retest session, consisting of two coding trials and one speed-motor trial, was administered in the same manner.

\section{SUBJECTS}

Three groups of 12 children each were tested under identical test conditions. Group D contained six boys and six girls, all severely hearing-impaired, with ages between 9 and 12, who were judged by their teachers to be accomplishing expected academic progress. Matched to this group in age and sex were 12 children (Group S) from the same school who also were severely hearing-impaired and who had been considered by their teachers to have additional apparent learning problems superposed on their hearing impairment. These children generally achieve lower IQ scores than those in the division from which Group D were drawn (Elliott, 1967); however, the validity of these scores is uncertain and school personnel view the learning progress of these children as poorer than their aptitudes would warrant. These two groups of children had originally been enrolled in different divisions of the school; the division from which Group $S$ was selected is known
Table 1

Test Performance

Groups

Hearing-Impaired

Number I tems Correct

Coding Trials

ist

M

SD

14 th

$M$

SD

Retest

Motor-Speed Trials

$1 \mathrm{st}$

M

SD

Retest

$\mathrm{M}$

SD

\begin{tabular}{rrr}
34.8 & 28.2 & 37.3 \\
6.0 & 8.5 & 5.7 \\
58.2 & 38.5 & 57.3 \\
8.8 & 14.8 & 8.7 \\
58.7 & 37.1 & 58.7 \\
9.6 & 12.9 & 10.5 \\
& & \\
102.4 & 74.2 & 98.3 \\
9.1 & 25.6 & 11.9 \\
106.4 & 79.2 & 101.3 \\
7.0 & 20.6 & 11.3 \\
\hline
\end{tabular}

all groups. Standard deviations of all measures were larger for Group $\mathrm{S}$, indicating greater he terogeneity than in either Group D or $\mathrm{N}$. When performances are considered in terms of individual improvement ratios (Trial 14:Trial 1) the arbitrary value of 1.545 divides Ss so that only two of the D group have improvement ratios smaller than 1.545 and only two of the $S$ group have larger. In comparison, exactly half of the children in Group $\mathbf{N}$ have improvement ratios larger than 1.545. Performance gains during the two sessions were main tained by all groups during the retention interval with no significant loss or gain after one warm-up trial in the retest session. Finally, data for all speed-motor trial, their slowness cannot be attributed exclusively to cognitive diffi. culties.

The ability measured by the coding subtest may be an inherent characteristic of the individual. The finding that academically successful deaf children demonstrate greater relative improvement under conditions of rewarded practice than do "low achievers" while academically successful children with normal hearing display a wide range of improvement ratios under the same circumstances (i.e., $83 \%$ of Group D, $17 \%$ of Group S, and $50 \%$ of Group $N$ achieved improvement ratios greater than the cutting score) suggests that the skill measured by this subtest becomes more critical when the 
GL ASSER, A. J., \& ZIMMERMAN, I. L. Clinical interpretation of the WISC. New York: Grune and Stratton, 1967.

GRAHAM, E, E. Wechsler-Bellevue and WISC scattergrams of unsuccessful readers. Journal of Consulting Psychology, 1952, 16, 268-271.

HARTMAN, J. S., \& ELLIOTT, L. L. Performance of deaf and hearing children on a short term memory task. Psychonomic Science, 1965, 3, 373-374.

HARTUNG, J. E. Visual perceptual skills, trigram pronouncibility and the reading achievement of young deaf children. Unpublished doctoral dissertation, Washington University, St. Louis, Mo., 1968.

OLSON, J. R. A factor analytic study of the relation between the speed of visual perception and the language abilities of deaf adolescents.
Journal of Speech \& Hearing Research, 1967, $10,354-360$

ROBECK, M. C. Subtest patterning of problem readers on the WISC. California Journal of Educational Research, 1960, 11, 110-115.

WITHROW, F. B. Immediate memory span of deaf and normally hearing children. Exceptional Children, 35, 1, 1968.

\section{NOTE}

1. We wish to thank te achers and children of the Webster College School for their assistance and cooperation during the fall and winter of 1967-1968. This research was supported in full by a U.S. Public Health Service, Department of Health, Education and Welfare research grant from the National Institute of Neurological Diseases and Blindness.

\section{The interaction of response $M$ and \%ORM in paired-associate learning}

DONALD $R$ YELEN and DELPHINE YELEN, Washburm University, Topeka, Kans. 66621

The interaction of response meaningfulness (M) and percentage occurrence of response members (\%ORM) was investigated in nvo experiments. Results of both experiments indicated that early in training high-response $M$ items produced larger differences between FORM groups than low-response $M$ items, but that the reverse was true late in training. Previous failures to obtain a significant $\mathbf{M}$ by $\%$ ORM interaction were attributed to the use of response measures which are not sensitive to the reversal of the interaction with training.

There has been relatively little empirical support for the presence of an interaction between response meaningfulness $(M)$ and the percentage occurrence of response members (\%ORM) in paired-associate learning situations. Some support for a $\mathbf{M}$ by $\%$ ORM interaction has been inferred from a comparison of the materials and results of the studies which first manipulated \%ORM. That is, Schulz \& Runquist (1960), using adjectives, reported small differences between their \%ORM groups, while Goss,
Morgan, \& Golin (1959), using nonsense syllables, reported relatively large differences between their \%ORM groups. Since the effects of \%ORM were greater with low-M materials than with high-M materials it was inferred that $M$ interacted with \%ORM. However, subsequent studies which simultaneously manipulated response $M$ and $\% O R M$ either failed to find a $M$ by $\% O R M$ interaction (Wilcoxon, Wilson, \& Wise, 1961), or reported relatively weak interactions of response $\mathrm{M}$ and \%ORM (Goss, Nodine, Gregory, Taub, \& Kennedy, 1962).

The present experiments were conducted to determine if the $\mathrm{M}$ by \%ORM interaction had been masked by the trials-to-criterion measure used in all of the previous investigations. If the $\mathrm{M}$ by $\% O R M$ interaction is confined to the early stages of learning, as suggested by Schulz \& Runquist (1960), it is possible that the interaction would not be reflected in a trials-to-criterion score. Therefore, the present experiments used the number of correct responses during paired-associate learning trials as the response measure.

\section{EXPERIMENT 1}

\section{Materials}

All Ss learned the same eight-item paired-associate list. The stimuli were eight high meaningful trigrams (Noble, 1960): the responses were four low ( $m$ ranging from 2.69 to 3.21) and four high ( $m$ ranging from 9.77 to 10.87 ) meaningful dissyllables (Noble \& Parker, 1960).

Procedure

Ten male and 10 female introductory psychology students were randomly assigned to each of two experimental conditions $-100 \%$ ORM and $25 \%$ ORM. The Ss leamed by the study-test method. In the $100 \%$ ORM condition, each stimulus appeared with its response on study trials and each stimulus appeared alone on the succeeding test trial. In the $25 \%$-ORM condition, one high- $M$ response and one low-M response occurred on each study trial. No response member was repeated until all other responses had been presented, thus each response occurred once in every four study trials. Each stimulus appeared alone on each of the test trials. For both groups, four different orders of items were used on study trials and four different orders on test trials to prevent serial associations.

A Stowe memory drum was used to present the lists. The items appeared at a $2-\sec$ rate and the intertrial interval was $4 \mathrm{sec}$. All Ss received a total of eight study and eight test trials.

Results

An analysis of variance was performed on the number of correct responses on each of the eight trials with $\%$ ORM as a between-Ss effect and Response $M$ and trials as within-Ss effects. A significant triple interaction of $\mathrm{M}$ by $\%$ ORM by Trials (presented in Fig. 1) was obtained ( $F=3.32$, df $=7 / 266, p<.01)$. As the figure shows, performance was higher under $100 \%$ ORM conditions than under $25 \%$ ORM conditions, and better with high.M responses than with low-M

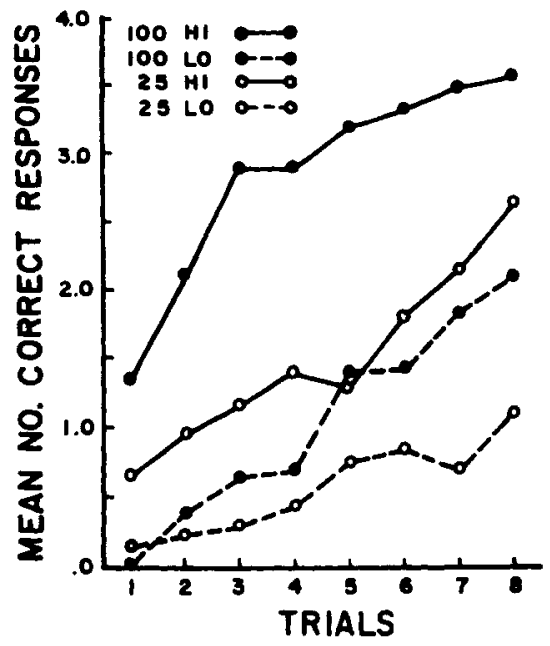

Fig. 1. Mean number of correct responses as a function of Response $M, \% O R M$, and trials. 